\title{
A PÓS-GRADUAÇÃO EM DIREITO NA UNIVERSIDADE DE SÃO PAULO: INTERPRETANDO SEU CINQUENTENÁRIO
}

\author{
José Reinaldo de Lima Lopes ${ }^{1}$
}

Situando-se historicamente

Falar de 50 anos da pós-graduação em Direito na USP significa imaginar o início dessa história no contexto da reforma universitária brasileira de 1968. No texto a seguir pretendo recuperar um pouco da história da pós-graduação inserindo-a nesse processo de reforma desencadeado em 1968, o qual levou alguns anos para se consolidar e ocorreu muito conflitiva e limitadamente no ápice da repressão política e restrição da vida democrática promovidas pela ditadura de 1964. Foi em função da reforma universitária que se estabeleceu o programa de pós-graduação em direito da USP e é pelas metas que ali surgiram que se pode avaliar seu desenvolvimento. Em função dessa vinculação da pós-graduação com a reforma, trato em seguida das mudanças necessárias na cultura da faculdade de direito para que tivesse início sua conversão de instituição principalmente de ensino em instituição de ensino e pesquisa. A reforma deveria ter atingido o curso de graduação e de modo articulado também o doutorado. Finalmente, pretendo sugerir alguns caminhos abertos atualmente diante do fato da massificação dos cursos de pós-graduação em Direito no Brasil e dos desafios colocados pela pesquisa dentro de uma escola profissional.

O curso de doutorado em Direito na USP é mais antigo do que a reforma universitária, assim como a Faculdade de Direito da Universidade é a mais antiga escola superior em São Paulo. ${ }^{2}$ Ele existia em formato para o qual a pesquisa era atividade individual cujo propósito era esclarecer temas para o próprio pesquisador. Com esse peso e tradição a história constrange muito nossa experiência: quanto mais longa uma história, mais constrangimentos cria, mais se cristalizam suas tradições, e quanto mais tradição, mais pesado o passado.

1 Professor Titular do Departamento de Filosofia e Teoria Geral do Direito da Faculdade de Direito da Universidade de São Paulo.

2 Criada em 1827 simultaneamente com a Faculdade do Recife (instalada inicialmente em Olinda), foi antecedida - como escola de nível superior - pela Faculdade de Medicina da Bahia e pela Escola de Marinha do Rio de Janeiro. Antes da transferência da corte para o Brasil a Coroa portuguesa não permitira a instalação de cursos superiores em suas colônias americanas. Os colégios jesuítas, especialmente os do Salvador e do Maranhão poderiam ter sido alçados ao mesmo estado do de Évora, mas não conseguiram aprovação. Em 1800 Dom Azeredo Coutinho (1742-1821) instituíra um seminário em Olinda, único centro de ensino capaz de formar jovens intelectualmente preparados no Brasil, visto que os jesuítas, antes encarregados do ensino, haviam sido expulsos em 1759 e seus colégios abandonados. 
O passado da Faculdade de Direito - uma tradição propriamente, e como tal transferida de geração em geração - pesa não pouco. Diferentemente de outras escolas integradas na Universidade de São Paulo a partir de 1934, a Faculdade de Direito filiava-se a uma corrente de pensamento bastante consolidada. Gostaria de escrever um pouco sobre essa tradição. Como sou atualmente um dos professores mais velhos da Faculdade de Direito, experimentei mudanças graduais no sistema. Quando cursei o bacharelado entre 1971-1975, auge da ditadura não havia grupos de estudo, nem de pesquisa, nem vida intelectual para o corpo docente. Tudo silencioso e silenciado. Ingressei na pós quando se suspendia o AI-5 e começava a discutir-se a anistia e a volta dos exilados. Outros tempos. Sou da primeira turma do curso de graduação que ingressou pelo sistema de vestibular unificado em que já não se exigia o latim; fui da segunda turma a passar pela reforma do currículo de 1973, que criou as áreas de concentração para o último ano do bacharelado e as disciplinas optativas (eletivas), e quando ingressei na pós, em 1979, havia ainda bem definida a necessidade de cursar disciplinas na área de concentração escolhida (cada departamento equivalia a uma área), e o exame de qualificação era uma espécie de exame "de universa", que obrigava o aluno a levar a sério todas as disciplinas cursadas.

A reforma universitária

A reforma universitária de 1968 (Lei 5.540/1968) veio alterar o panorama de modo radical. Ela pretendia aproximar a universidade brasileira do modelo de maior sucesso no mundo, a universidade americana. ${ }^{3}$ A Universidade de São Paulo, primeira no Brasil a incorporar-se em torno de uma Faculdade de Filosofia, havia seguido o modelo europeu e nela os professores catedráticos reproduziam o estilo do "professor proprietário" de sua "cadeira". O catedrático escolhia seus assistentes de forma pessoal e livre e os preparava para um dia sucedê-lo.

A reforma pôs fim, oficialmente, às cátedras (e aos catedráticos) e em seu lugar criou os departamentos, que deveriam ser não apenas centros administrativos, mas núcleos de orientação didática e de pesquisa. Os Conselhos decidiriam as disciplinas a serem ministradas, seus programas, as formas de recrutamento de professores, e as direções das pesquisas. Tirava-se do catedrático o controle exclusivo e absoluto da direção do ensino. Esse era o modelo norte-americano, no qual se via, e ainda se vê, essas orientações com certa clareza: diferentes escolas têm diferentes interesses, e os diversos

\footnotetext{
3 A universidade de pesquisa norte-americana sofreu, no seu nascimento ao final do século XIX e começo do século XX a influência da universidade de pesquisa alemã, estabelecida também no século XIX. Para o caso das faculdades de direito v. Rabban, D. Law's history: Americann legal thought and the transatlantic turn to history. Cambridge: Cambridge University Press, 2013, passim.
} 
departamentos espalhados pelo país são conhecidos pelas orientações diversas que têm, pela concentração em alguns temas e não em outros, e pela seleção de seu corpo docente para dar continuidade a tais linhas ou para alterá-las quando julgar necessário.

Para os que nos acostumamos com a estrutura departamental não é simples entender o que era a cátedra e como funcionou durante tanto tempo. Na Faculdade de Direito, então, a coisa foi mais complicada, porque embora abolidas as cátedras, os antigos catedráticos continuaram a ocupar seus lugares e continuavam a exigir no dia a dia o mesmo tratamento de que antes se beneficiavam. E pelo menos a primeira geração de novos titulares, de meados dos anos 1970 até os anos 2000 receberam de seus professores a mesma cultura. Vários deles eram formados no Brasil mesmo, de modo que sua exposição a um ambiente universitário era restrita ao que viam acontecer por aqui. Alguns obtiveram seus doutorados fora, na Europa em geral, onde o modelo vigente nada tinha a ver com o sistema universitário norte-americano, base e padrão de nossa reforma de 1968. Com isso, a cátedra abolida sobrevivia nas práticas cotidianas transformando os departamentos em arenas de conflitos entre catedráticos. A tais conflitos de influência e controle do aparelho burocrático somavam-se os que eram oriundos da divisão política a que a ditadura havia submetido o país, na medida em que num regime autoritário os opositores transformam-se de adversários em inimigos a serem eliminados, não apenas afastados e contidos.

Para bem entender as circunstâncias é preciso saber que a cátedra era um cargo público que dava a seu ocupante, o catedrático, um poder incontrastável e incontrolado não apenas na direção da disciplina, dos pontos, dos assuntos e temas, mas especialmente na escolha de quem o seguiria ou não. O catedrático elegia soberanamente seus assistentes e estes eram treinados para reverenciá-lo e com o passar do tempo, sucedê-lo. Ele controlava as entradas. Esperava que seus assistentes o tratassem com a deferência devida, repetindo o quanto possível o que dele ouviam. A atitude era de subserviência intelectual. $\mathrm{O}$ doutorando era, portanto, uma escolha do catedrático: o regime de cátedra estendia-se ao doutorado. Como na Faculdade de Direito não havia pesquisa institucional (coletiva), o controle dos catedráticos era enorme.

No parecer do grupo de trabalho encarregado de preparar a reforma universitária nacional, falava-se da cátedra como de um regime de "enfeudamento do saber". ${ }^{4}$ Em seu lugar deveriam entrar os departamentos, unidades colegiadas para decidir as questões acadêmicas (programas, disciplinas, pesquisas) das quais poderiam participar com direito a voto e voz os professores em diversas fases da carreira.

$\mathrm{Na}$ esfera dos departamentos seriam organizados os cursos de pósgraduação, "sistemáticos", dizia o grupo de trabalho da reforma nacional, para formar

$4 \quad$ Reforma universitária: Relatório do grupo de trabalho criado pelo Decreto n. $62.937 / 68,1983$, p. 38. 
os novos quadros docentes e permitir que o sistema universitário se reproduzisse e expandisse. Naquela altura percebia-se que as universidades deixadas a si mesmas não seriam capazes de criar o sistema de pós-graduação, por falta de recursos materiais e pessoais: convinha que a iniciativa e o estímulo viessem do próprio Governo Federal e nessa percepção se encontra a origem do papel atribuído então ao Conselho Nacional de Pesquisa (CNPq) e em seguida à CAPES - Coordenação de Aperfeiçoamento do Pessoal de Nível Superior.

Como o processo se deu em meio à ditadura é bom lembrar que dele foram afastados os professores e alunos perseguidos pelo regime, cassados, exilados, presos, desaparecidos alguns. Em resumo, a abertura dos departamentos ocorreu num ambiente em que muita gente não via real possibilidade de participação.

Essa reforma, na qual a USP teve, no momento da implantação, um papel exemplar, era uma tentativa de aproximar o Brasil do modelo universitário de maior sucesso naquela altura, o norte-americano. Assim como as universidades americanas de final do século XIX haviam emulado as universidades alemãs, ${ }^{5}$ era chegado o momento de o Brasil emular as universidades americanas. A reforma foi implantada, porém, no momento mais duro da repressão da ditadura, de modo que muitos dos melhores cérebros brasileiros haviam sido exilados, cassados, silenciados, e nas universidades a perseguição a alunos engajados em movimentos estudantis, políticos ou culturais, criou um silêncio sepulcral nas faculdades. Quem frequentou a faculdade de direito nos primeiros anos da década de 1970 lembra-se bem do deserto de ideias e de cultura em que se havia convertido. Os frutos da modernização seriam colhidos muito mais tarde, mas essa mancha inicial comprometeu grande parte do processo. $\mathrm{Na}$ medida em que uma universidade precisa de liberdade para pesquisar, para criar e debater, a reforma universitária não poderia gerar novidades de peso. Gerou uma reforma administrativa, burocrática, mas como a reforma se deu sobre corpos docentes e discentes silenciados, ela terminou sendo limitada. Não é de admirar, pois, que o fim das cátedras, no plano formal, nem sempre tenha significado liberação de energia criativa no plano substancial da vida acadêmica.

\footnotetext{
V. por exemplo Rabban, D. Law's history: Americann legal thought and the transatlantic turn to history. Cambridge: Cambridge University Press, 2013. Só em 1999 a União Europeia resolveu assumir uma reforma de seu sistema universitário que o aproximasse ao modelo norte-americano, pela "Declaração de Bolonha", a qual desencadeou um longo processo de mudanças. O processo não é apenas o de unificação ou harmonização dos modelos nacionais, mas vai na direção da aproximação de sua estrutura àquela cujo sucesso foi comprovado nos Estados Unidos no século XX. No Brasil, a despeito da necessidade de mudanças da universidade, o fato de a reforma ser finalmente realizada pelo regime militar com o apoio do governo dos Estados Unidos por meio dos famosos acordos MEC-USAID deu muito pano para manga e muita oposição política, especialmente por parte do movimento estudantil, reprimido pelo regime. A reforma foi maculada por essa origem.
} 
Foi visível o esvaziamento dos Departamentos de suas atividades propriamente acadêmicas, de ensino e pesquisa, e se converteram em passagem obrigada apenas dos trâmites burocráticos. Conservando o monopólio de processos administrativos, foram durante muito tempo o campo de batalha dos catedráticos, interessados em avançar suas respectivas pautas pessoais, mais do que em transformá-los em lugares de efetiva participação e discussão.

A reforma universitária havia sido gestada durante os anos de 1960, em plena guerra fria, na efervescência do movimento estudantil e em meio a mais uma onda de discussões políticas a respeito do desenvolvimento nacional. $\mathrm{O}$ desenvolvimento tornara-se um polo de discussões. Nele o direito jogava um papel relativamente marginal, pois se tratava em primeiro lugar de planejar o desenvolvimento - isto é, o crescimento econômico, ${ }^{6}$ embora a instalação das grandes empresas multinacionais dependesse de mudanças importantes tanto no regime jurídico quando no papel jogado pelos advogados, que se tornariam conselheiros dessa fração do capital. Era também o tempo das formulações de Celso Furtado, de um lado, e de Roberto Campos de outro. Se o direito era pouco interessante para os economistas e tecnocratas, era, contudo, alvo de atenção dos norteamericanos, sabedores de que sem instituições e sem manipuladores profissionais dessas instituições, a instituição mais ampla, o mercado capitalista, não tem como se estabelecer nem funcionar.

A reforma e a ditadura - modernização e projeto norte-americano

Em meio a esse espírito reformador e modernizador adota-se um ataque ao ensino jurídico tradicional. Diante do desenvolvimentismo assumido pelo regime militar, era preciso contara com o sistema jurídico para promover mudanças. O direito brasileiro era ainda fortemente influenciado pelo direito público francês: o direito administrativo era visto especialmente com a desconfiança típica de quem forma os administrativistas para controlar e conter o poder do Estado, não para viabilizar o poder público como organizador do mercado. O nascente direito econômico precisava de advogados e juristas aptos a manejar o direito de um Estado ativo. O direito constitucional brasileiro era, de muitos modos, diferente do francês, e a constituição de 1946 e as cartas editadas pelos militares nos anos 1960 o afastavam sempre mais

6 As teorias da modernização estavam na moda e nessa década aparece Cardoso, F. H. Política $e$ desenvolvimento em sociedades dependentes - Ideologias do empresariado argentino e brasileiro. São Paulo: Tese - Universidade de São Paulo, 1968. Tais teorias tinham grande popularidade nos tempos da guerra fria e tinham nos Estados Unidos seu mais importante ideólogo, Walter Rostow. V. a respeito Motta, R. P. As universidades e o regime miliar. Rio de Janeiro: Zahar, 2014, p. 110-192. Sobre as teorias da modernização no Brasil ver Guimarães, A. S. Classes, raças e democracia. São Paulo, SP: Editora 34, 2002, p. 13-45. 
daquela matriz. Sem contar que a estrutura social e política brasileira era específica, como devem ser todas as experiências históricas.

Se bem que tivesse havido muitos professores e juristas brasileiros envolvidos numa espécie de "realismo jurídico", as escolas haviam permanecido em grande parte intocadas em seus métodos, tanto de ensino quanto de pesquisa. Autores como Oliveira Viana, Francisco Campos, Hermes Lima, ou mesmo Santiago Dantas, críticos da cultura jurídica de seu tempo, não desenvolveram eles mesmos pesquisas inovadoras nem fizeram escola dos métodos inovadores que exaltavam. Em outras palavras, valiam-se da leitura de autores de outras disciplinas, como a ciência política ou a economia, mas não produziram pesquisa interdisciplinar autônoma e nova.

Ocorreu então o cerco norte-americano às faculdades brasileiras, o qual teve diversas frentes. Uma delas foi a missão de que participou Oscar Barreto com vários professores brasileiros e que será analisada na seção seguinte. Outra foi a experiência do CEPED (Centro de Estudos e Pesquisas no Ensino do Direito), estabelecido no Rio de Janeiro em 1966. ${ }^{7}$ O CEPED foi organizado como verdadeira expedição modernizadora do que parecia aos olhos dos norte-americanos envolvidos o inóspito e atrasado mundo jurídico brasileiro. Ao contrário das elogiosas palavras de Karl Loewenstein, no momento em que os Estados Unidos cultivavam a estratégica aliança brasileira no Atlântico $\mathrm{Sul},{ }^{8}$ para os representantes estadunidenses do período da Guerra Fria, esta nossa terra papagalis precisava de uma boa reforma em sua cultura jurídica. Fundado em 1966 por um grupo de jovens professores norte-americanos, alguns dos quais mantiveram durante longos anos relações com seus colegas brasileiros, o Centro fez uma experiência de curso de pós-graduação lato sensu, não de doutorado nem de mestrado, com a ajuda de então jovens advogados brasileiros. Alguns deles vieram a se consolidar como grandes advogados, participaram de algumas reformas legais dos anos 1970 (como a da lei de sociedades anônimas e da lei de mercado de capitais) e dois deles, no início dos anos 2000, criaram e dirigiram as duas faculdades de direito da Fundação Getúlio Vargas. ${ }^{9}$

7 O CEPED deve ser entendido no mesmo contexto da reforma universitária, pois tem um ideário politicamente definido: reformar o direito brasileiro e seus profissionais dentro da ótica de desenvolver "um grupo de estudantes e professores simpáticos aos Estados Unidos", como lembra Motta, R. P. As universidades e o regime miliar. Rio de Janeiro: Zahar, 2014, p. 114.

8 Cf. Loewenstein, K. Brazil under Vargas. New York, NY, USA: The MacMillan Company, 1944, passim.

9 Foram eles Ary Osvaldo Mattos Filho e Joaquim de Arruda Falcão. Essa história está bem contada em Lacerda, G.; Falcão, J.; Rangel, T. Aventura e legado no ensino jurídico. Rio de Janeiro: FGV Direito Rio, 2012. Os dois jovens advogados eram Joaquim de Arruda Falcão e Ary Osvaldo Mattos Filho, respectivamente fundadores e primeiros diretores das escolas de direito da FGV no Rio de Janeiro e em São Paulo. Dois dos professores norte-americanos que participaram da experiência, David Trubeck e Henry Steiner, têm importantes depoimentos na obra. Outros participantes do experimento foram Alberto Venâncio Filho e Alfredo Lamy. Venâncio Filho terminou por escrever uma história do ensino jurídico brasileiro que serve até hoje de referência: VenAncio Filho, A. Das arcadas ao bacharelismo. 2. ed. São 
Havia certa pressa em modernizar o direito e o ensino jurídico brasileiros, mas, como reconhecem os comparatistas, a transferência fatiada e fragmentada de instituições não costuma dar os resultados esperados. Citemos, no caso do diálogo entre sistema norte-americano e sistema brasileiro, apenas alguns pontos. O primeiro deles diz respeito à cultura do precedente: no Brasil, como na Europa Ocidental, usa-se a jurisprudência como fonte de argumentos, mas os juízes e tribunais não se consideram vinculados às decisões anteriores ou de instâncias superiores. Em resumo, não há um "sistema" de precedentes. Por isso, os alunos de Direito não sabem distinguir um obiter dictum de uma regra. E não se insiste nas diferenças circunstanciais dos casos. Um segundo ponto diz respeito à limitada, ínfima mesmo, presença do processo por júri entre nós. Como consequência, aquilo que nos Estados Unidos é muito desenvolvido, a disciplina autônoma de produção de provas (evidence) e suas técnicas de exame das testemunhas (cross examination), no Brasil não existe absolutamente. A oralidade do processo, que se impõem necessariamente nos julgamentos por jurados, no Brasil é apenas uma aspiração. Por isso, a despeito do que dizem nossos manuais, nosso processo é ainda muito mais próximo do processo inquisitório do que do processo adversário. A produção das provas é feita para um juiz, cujo treinamento é igual ao dos advogados do caso, e não para um público amplo, diante do qual seria possível mostrar vivamente os defeitos reais das provas trazidas pelas partes, e para quem o interrogatório de uma testemunha é algo vivo e significativo. A tradição inquisitorial revela-se de modo exemplar no fato de os acusadores (ministério público) sentarem-se ao lado do juiz, e não diante dele! E o que dizer do sistema de jurisdição administrativa? Difere totalmente do norte-americano e nunca foi alterado, desde a reforma da justiça promovida em 1890 por Campos Salles!

A reforma do ensino jurídico teve sorte semelhante: o ensino adaptouse, mas como foi mantido a escola profissional do Direito sem um college anterior, muitas das melhores intenções foram frustradas. Os alunos chegam aos bancos universitários sem o treinamento adequado, sem habilidades analíticas desenvolvidas, sem familiaridade com o pensamento clássico. Não se consegue recuperar nada disso nos cinco anos dedicados ao estudo do Direito vigente, comprometidos com o excesso de disciplinas e a preocupação (compreensível, mas precoce) de colocação no mercado de trabalho. Em resumo, o modelo implantado dependia de mudanças culturais que não ocorrem a não ser em longa duração.

Paulo: Perspectiva, 1982 (primeira edição em 1977). 
A reforma universitária na USP e na Faculdade de Direito - de instituição de ensino para instituição de pesquisa

Como em todo transplante de instituições, fácil é transplantar um desenho ou projeto, difícil transplantar a cultura, que é, afinal de contas, o que põe o projeto em andamento. E na Faculdade de Direito de São Paulo não foi diferente. O grande executor da reforma na USP foi Miguel Reale, da Faculdade de Direito e que, ao lado de muitos empreendimentos importantes, teve que acomodar a estrutura departamental aos catedráticos existentes. Obrigar catedráticos, ainda que jovens, formados no antigo modelo e que haviam sonhado com o dia em que disporiam de poder e influência para fazer o que quisessem e ainda "fazer seus sucessores", obrigá-los a conviverem nos departamentos nos quais sua vontade não contaria de maneira imediata, não foi nada fácil. ${ }^{10} \mathrm{E}$ era preciso reformar não apenas o aparelho, mas também o ensino. É o assunto da próxima seção.

\section{Os relatórios de Oscar Barreto e a reforma na USP}

Apesar de seu tamanho e de suas tradições, a Universidade de São Paulo foi, no entanto, rápida em adaptar-se à reforma, em boa parte devido ao fato de Miguel Reale, professor da Faculdade de Direito, ativo na vida política e simpático ao regime de 1964, ${ }^{11}$ ocupar naquela altura o cargo de Reitor da USP. Era homem de ação e iniciativa, para além de professor. O Decreto Estadual n. 53.326, de 16 de dezembro de 1969 instituiu o novo estatuto da Universidade de São Paulo, dando-lhe a estrutura departamental (art. 45-53), fixando a existência de cursos de pós-graduação (art. 64, 70-80), abolindo as cátedras e transformando-as em cargos de titulares (art. $85 \mathrm{c} / \mathrm{c}$ art. 136). ${ }^{12}$ Decretada a reforma da USP, passou-se à adaptação da Faculdade de Direito ao novo modelo e nesse momento o velho curso de doutorado foi rapidamente substituído pelo novo sistema.

Oscar Barreto esteve em 1968, patrocinado pelo governo dos Estados Unidos, num grupo de professores levados a estudar os novos métodos de ensino, uma vez que lá - nos Estados Unidos - o antigo "método do caso" parecia ser substituído, pois manifestava certo esgotamento. De fato, embora sendo o método preferido e mais divulgado nas escolas de Direito não parecia formar integralmente os alunos. O método, diz Gordley, transforma o aluno num Carneades, o cético, ou num "Billy the Kid": ele

\footnotetext{
10 O processo é narrado em suas memórias: Reale, M. Memórias - A balança e a espada. São Paulo: Saraiva, 1987 , v. 2, p. 187-215.

11 Idem, ibidem, p. 105-121.

12 Este estatuto vigorou até 1988, quando no gozo da autonomia universitária e já sob a Constituição Federal de 1988, o Conselho Universitário aprovou o novo estatuto, deu a público a Resolução n. 3.461, de 7 de outubro de 1988 .
} 
pode abater qualquer argumento contrário, mas não tem nada substantivo a respeito do Direito para colocar no lugar. ${ }^{13}$

Em seu relatório apresentado à Faculdade de Direito na sua volta, ${ }^{14}$ ele termina por sugerir diversas mudanças no ensino de nossa faculdade, inclusive (a) a introdução do "método do problema", (b) a flexibilização do currículo, (c) a ampliação de trabalhos práticos e exercícios sobre variados materiais jurídicos, (d) exigência de tempo integral para, pelo menos, um terço dos professores da faculdade, (e) atualização, ampliação e incentivo para uso das bibliotecas, (f) integração da economia e da ciência política na escola de Direito. O método do problema não seria o método do caso exatamente, mas um aperfeiçoamento ou melhoramento daquele. Como não havíamos feito a experiência do método do caso, seria de se duvidar que o novo método fosse facilmente assimilado. Isso não obstante, propôs diversas outras alterações, e fez importantes observações sobre o sistema estadunidense. Talvez por isso mesmo, quando alguns anos depois, em 1972, foi proposta a mudança do currículo do curso de graduação (bacharelado), terminou sendo de sua autoria o relatório do tema. ${ }^{15} \mathrm{O}$ currículo abria a possibilidade de os alunos escolherem áreas de especialização no quinto ano, mantidos os quatro primeiros anos com um programa fixo, destinado a cobrir o essencial das diversas disciplinas. Continuava a ser um curso panorâmico, articulado em torno dos grandes monumentos legislativos (código civil e penal, comercial e legislação societária, códigos processuais, etc.).

Pós-graduação numa escola profissional?

A pós-graduação, tendo de enquadrar-se nos moldes da reforma, devia necessariamente aproximar-se do modelo norte-americano. Mas não podia fazê-lo sem suas peculiaridades. Como nos lembram os comparatistas, leis e desenhos institucionais podem ser facilmente importados e copiados, mas não se importam com a mesma facilidade a cultura e o contexto em que essas leis e instituições se encontram em outros lugares. Assim foi com a pós-graduação em Direito. O regime norte-americano depende da existência de um sistema de ensino superior de dois níveis muito claros de cursos: o de artes liberais, bastante aberto e com duração de cerca de quatro anos, em que os estudantes são familiarizados com um ensino de nível superior. Para quem escolha as humanidades, oferecem-se cursos sobre os clássicos (da política, da filosofia,

13 Cf. J. Gordley. Mere brilliance: the recruitment of law professors in the United States. The American Journal of Comparative Law, 41, 1993, p. 367-384.

14 BARRETO, O. Novos métodos em ensino do direito: a experiência norte-americana. Revista da Faculdade de Direito da Universidade de São Paulo, n. 63, 1968, p. 335-378.

15 BARRETO, O. Plano de reforma do currículo do curso de graduação em direito. Revista da Faculade de Direito da Universidade de São Paulo, 67, 1972, p. 115-133. 
da literatura) e cursos instrumentais para o desenvolvimento de habilidades (raciocínio analítico, expressão e escrita acadêmica, etc.). Esses cursos ministrados em colleges em geral não habilitam seus egressos a profissões específicas. Já os cursos de pós-graduação são cursos propriamente ditos, mas não são seriados: as disciplinas são eletivas e nelas os estudantes são introduzidos em debates aprofundados e específicos, para se tornarem profissionais de uma certa área. Além dos cursos - seminários - ministrados em grupos sempre de pequenos números (de 6 a 18 alunos, no máximo) os alunos se envolvem em atividades de pesquisa. Isso exige deles dedicação integral ao curso.

A Faculdade de Direito adaptou-se ao modelo como pôde, sem perder sua característica principal: a de que sua graduação já forma profissionais. Com isto, no curso de pós-graduação o aluno já vem formado e dispõe de certo entendimento do que é o Direito. Por isso, no final dos anos 1970 e nos anos 1970 a Faculdade de Direito oferecia ainda um curso de pós-graduação lato senso, chamado especialização. Nele não se exigida pesquisa dos alunos e seu propósito era mais modesto, embora não menos sério: produzir especialistas em certas áreas, de modo a elevar a qualidade do exercício profissional. Mas essa experiência foi encerrada. Talvez devesse ter se convertido em um mestrado profissional. De todo modo, a USP passou a oferecer apenas o curso de pósgraduação acadêmico.

A pós-graduação e seus desafios

Essa foi uma parte da história da implantação de nossa pós-graduação, com circunstâncias compartilhadas pelo Brasil todo. Os tempos mudaram e hoje, depois de muitas décadas, o processo fez surgir novos desafios. Um deles diz respeito à relação entre pesquisa e mercado profissional, outro à possibilidade de massificarmos a pósgraduação e mesmo assim estimularmos a pesquisa.

Uma escola profissional com pesquisa?

A Faculdade de Direito é uma escola profissional, e a tensão entre um ensino profissional - que deseja ser de qualidade, para o vasto mercado de profissões jurídicas - e a pesquisa propriamente dita nunca se explicitou adequadamente, uma vez que a imensa maioria dos professores era profissional e dedicava-se mais a atividades profissionais do que a pesquisa. A pesquisa era uma espécie de subproduto ou resultado colateral da atividade profissional, e o tempo que os professores dedicavam à faculdade era ainda pequeno. A imensa maioria dedicava-se apenas a tempo parcial, dividindo suas tarefas entre a Faculdade de Direito, as atividades profissionais de advogado, juiz ou promotor, e outras faculdades de Direito. Muitos deles eram professores nas outras 
faculdades de prestígio em São Paulo, como a Pontifícia Universidade Católica ou a Universidade Presbiteriana Mackenzie.

A pesquisa - ligada à pós-graduação - não pode ser a mesma pesquisa de que falamos quando nos referimos ao simples estudo ou aprendizado de alguma coisa que ainda não conhecemos. Dentro de uma escola profissional muito há que discutir sobre isso, pois é muito diferente a posição do profissional que opera um Direito vigente e a do pesquisador, cuja tarefa é colocar sob exame crítico o sistema vigente. Para que alguém se dedique à pesquisa é preciso que haja clareza quanto à natureza da própria ciência ou do conhecimento em seu campo, a natureza de seu próprio objeto, e de como se procede adequadamente dentro dele. ${ }^{16}$

A pesquisa e o método jurídico

A pesquisa é o principal resultado de uma pós-graduação. O Direito, sendo uma disciplina diferente das ciências naturais, das ciências formais e das próprias ciências sociais, merece que sua pesquisa seja tratada e avaliada de forma específica. A diferença entre Direito e ciências naturais, formais e sociais é evidente. ${ }^{17}$ Embora um jurista precise de dados e conceitos que lhe são fornecidos pelas outras ciências, seu próprio saber não é capaz de criá-los ou fornecê-los: um jurista precisa saber dos progressos feitos na biologia molecular, por exemplo, para poder incorporar na lei certos fatos, mas ele mesmo não é capaz de produzir o conhecimento sobre tais progressos. Qualquer falante competente de uma língua vale-se da lógica como os mais dedicados à inteligência artificial, mas o conhecimento jurídico em si não faz progresso nessa área. $\mathrm{O}$ olhar das ciências sociais difere do conhecimento jurídico porque este tem necessariamente pretensão normativa: o Direito, como disciplina, não pretende descrever mas orientar as ações. Dessa forma, a pesquisa em Direito não pode facilmente 'importar' os métodos das outras áreas do conhecimento universitário, apesar de poder e dever mesmo dialogar com elas. Por isso, refinar seu próprio método e num curso de pós-graduação tem um papel importante.

No caso da pós-graduação da USP, seu papel é revelado primeiramente pelo empenho de vários de seus professores, especialmente os mais jovens, de empenharse no diálogo com outras áreas do saber. Um dos exemplos mais significativos disso foi sua participação no desenvolvimento de uma área de estudos empíricos ou de pesquisa empírica em Direito. Boa parte dos professores que deram início a esse 'campo' foram

16 Cf. Hage, J. The method of a truly normative legal science. In: M. Van Hoeke. Methodologies of legal research: which kind of method for which kind of discipline? Oxford: Hart Publishing, 2011, p. 20.

17 Para uma visão geral cf. Van Hoecke, M. Legal doctrine: which method(s) for what kind of discipline. In: M. Van Hoecke. Methodologies of legal research: which kind of method for what kind of discipline? Oxfor: Hart Publishing, 2011, p. 1-18. 
formados no programa de pós-graduação em Direito da USP e hoje compõem seu corpo docente. Uma pesquisa nos bancos de dados disponíveis na rede mundial mostra que foram produzidas cerca de vinte (20) teses e dissertações e dois mil, trezentos e trinta e dois (2.332) artigos em pesquisa empírica em Direito. Pesquisa empírica em Direito é algo bastante discutido e discutível, mas sua existência revela um desejo de aperfeiçoamento da pesquisa. Houve um notável avanço nesse diálogo que se revela em iniciativas comuns de seminários, grupos de estudo e frequência de nossos alunos a disciplinas de outras unidades. Infelizmente a recíproca ainda não é equivalente, ainda recebemos em nossos seminários poucos candidatos de outras áreas. Mesmo assim, algum progresso foi feito.

As perguntas elementares nesse âmbito seriam primeiramente pela natureza mesma da pesquisa em Direito. Em que consiste a pesquisa jurídica? Em segundo lugar seria preciso refletir sobre os graus diferentes de pesquisa: o que é e como pode ser uma pesquisa básica em Direito? O que é e como pode ser uma pesquisa aplicada em Direito? ${ }^{18}$

Para enfrentar essas questões é indispensável formar uma ideia sobre as relações entre a prática jurídica profissional e a academia. Como pode a academia produzir algum conhecimento e que espécie de conhecimento produz? Numa escola profissional e numa disciplina profissional como o Direito, muitas das inovações jurídicas nascem não do gabinete do estudioso, mas do gabinete do advogado ou do legislador. $\mathrm{O}$ legislador, tempos atrás era esse misto de profissional e doutrinador: Teixeira de Freitas, José Nabuco, Coelho Rodrigues, Clovis Bevilaqua, Carvalho de Mendonça, Inglez de Souza, Santiago Dantas, Miguel Reale, e tantos outros foram legisladores, professores e práticos do Direito. O legislador não era um amanuense ou um aventureiro. As ideias que precisavam converter-se em lei surgiam na prática, não há dúvida, mas colocá-las adequadamente no todo do ordenamento e expressá-las elegante, concisa e precisamente era tarefa que não se delegava a qualquer um.

O paradoxo da massificação

Um aspecto que chama atenção atualmente é o da massificação, pois ela afeta a formação de novos pesquisadores e a pesquisa mesma. Particularmente porque seria fácil confundir a pesquisa em Direito com o simples estudo, especialização ou aprofundamento escolar dos profissionais em geral. Para enfrentar a questão é importante perceber de onde vem a pressão pela massificação da pós, as condições que ela encontrou e encontra no programa de Direito e de que modo a pesquisa efetiva pode fazer lhe fazer face. 18 Para uma revisão do debate sobre ciência básica e ciência aplicada v. Kaldewey, D., \& Schauz, D. Basic
and applied research: the language of science policty in the twentieth century. Berham Books. 
O desenvolvimento do programa de pós foi em boa parte o resultado dos esforços dos professores. Com o passar do tempo aglutinaram-se em torno deles diversos alunos, admitidos dentro dos números permitidos. Para cada professor admitiam-se - e admitem-se ainda - dez orientandos. À medida que o número de professores crescia, crescia também o número de alunos. Embora os alunos fossem atraídos primeiramente pela obra reconhecida de seus mestres, o certo é que sendo eles muitos tornou-se difícil articulá-los em um programa. E como os interesses dos professores também mudavam ao longo do tempo, acumularam-se alunos interessados em muitíssimos temas. Se isso é positivo pelo lado da capacidade de expansão do programa, que forma professores para muitas escolas pelo Brasil afora, é negativo pelo lado da pesquisa, pois a variedade de projetos dificulta, quando não impede sua aglutinação em torno de temas. O impacto dessa atividade dispersa é muito mais difícil de medir dentro dos respectivos campos. As mesmas qualidades da USP, como contar com professores altamente qualificados, sempre portadores do título de doutor, selecionados em concursos competitivos e relativamente numerosos para atender à demanda do curso de graduação (com cerca de dois mil, duzentos e cinquenta alunos matriculados), podem gerar efeitos negativos na pós-graduação quando esses números se transferem para a pós-graduação.

A situação em que nos encontramos poderia chamar-se, não sem um certo paradoxo, de uma "pós-graduação de massa". Trata-se de um paradoxo porque a pós-graduação foi inicialmente criada para gerar conhecimento novo, isto é inovador, e pessoal acadêmico, isto é, não dedicado primariamente ao mercado profissional tout court. Os sonhos e ideais de cinquenta anos atrás foram colocados em xeque diante de em alguns aspectos dessa produção em massa de doutores e mestres e consequentemente de seu impacto no ambiente em que se vêm formando.

Os problemas que se enfrentam na pós-graduação em Direito são nacionais, é bom que se diga, e têm a ver, em boa parte, com a "porta giratória" que uma escola profissional mantém com o mercado. Uma disciplina como o Direito tem dificuldades em reter seus mestres e doutores no ambiente de pesquisa, uma vez que o mercado de trabalho oferece atrativos muito grandes e não apenas atrativos financeiros. Claro, estes são muitos, mas penso também em atrativos de outra natureza, uma vez que em certas posições no mercado os profissionais do Direito dispõem de muito maior poder e influência do que seus professores. Hoje em dia são os representantes e procuradores do grande capital que legislam por encomenda ou por lobby para um universo variado de assuntos. Isso também atrai alguns.

A massificação afeta o próprio ideal dos seminários de pós-graduação. Deveriam consistir num exercício de discussão e aprofundamento dos teóricos do Direito. A pós-graduação no sentido estrito não é um curso profissionalizante, nem mesmo um curso de formação de professores de Direito apenas, uma espécie de "licenciatura" mais 
longa. No sentido estrito deveria ser, a meu juízo, o lugar de formação de pesquisadores. Pesquisadores não deveriam ser "técnicos glorificados" (glorified technicians), como dizem alguns. A perspectiva de um seminário de pós é, por isso, essencialmente teórica. Mesmo que seus temas sejam cotidianos, candentes, atuais, a teoria deveria impor aos participantes a capacidade de análise e abstração que lhes permitisse superar a discussão forense ou a discussão jornalística. Para tanto, pressupõe-se que haja um número limitado de participantes para que todos possam interagir ativamente. Não é aceitável num seminário de pós-graduação que os alunos não se manifestem. Num grupo de vinte e cinco ou quarenta alunos, como passou a ocorrer nos últimos anos, isso não é possível. A participação não pode restringir-se a dar uma opinião esporadicamente, mas a apresentar-se no debate com profundidade, acuidade, consistência e constância. Nada disso é possível em grupos massificados. A "porta giratória” e a massificação permitem que acorram aos seminários muitos despreparados, curiosos, que estão ali para "aprender" ou "aperfeiçoar-se", não para se tornarem pesquisadores propriamente. Se a "porta giratória" e a massificação permitem isso, elas também exigem: exigem que os níveis de os volumes de leitura sejam reduzidos.

Os alunos estão no curso de pós-graduação para desenvolverem pesquisas e se tornarem intelectuais autônomos (doutores). Os seminários de que participam seriam lugares em que conjugariam as pesquisas que fazem com as discussões relevantes, tanto dos clássicos quanto da produção mais recente. Os professores deveriam oferecer nos seminários essas portas de entrada para os alunos. Com o número realmente grande de professores com que conta a Faculdade de Direito isso seria perfeitamente possível de se fazer, desde que houvesse clara limitação do número de inscritos em cada disciplina. Os seminários deveriam ser também os locais para que pusessem a prova algumas de suas ideias e parte de suas pesquisas. Isso raramente acontece, da maneira como estão hoje colocadas as coisas. Assim, o programa deveria levar em conta essa limitação para também determinar o número de ingressantes. Digamos que desse ponto de vista a "oferta é inelástica".

Os alunos da pós-graduação em Direito deveriam ser majoritariamente dedicados integralmente ao estudo. Se alguns forem capazes de se dedicar também a atividades profissionais, isso não seria um impedimento. Mas os níveis de exigência deveriam ser tais que somente os excepcionalmente capazes e produtivos pudessem participar. Os outros deveriam ser dirigidos à especialização, ou ao mestrado profissional. A pós-graduação deve ser a estufa onde se cultiva conhecimento novo e se preparam pesquisadores e professores de Direito. Considerando que as novidades no Direito não precisam acontecer apenas nos gabinetes universitários é preciso, por meio dos projetos e linhas de pesquisa, integrar a produção acadêmica e a produção não acadêmica. Como professor de história do Direito que fui durante vários anos lembrava meus alunos de 
que algumas das invenções medievais de mais impacto e duração, como foram todos os institutos do crédito e da economia mercantil, não nasceram de estudos dos professores de Direito encerrados em seus escritórios anotando o Digesto, ou as Decretais. O crédito desenvolveu-se pela inventividade dos notários e dos comerciantes, mas essa inventividade foi posta à prova pelos juristas e dessa prova saiu fortalecida e ampliada. Hoje devemos pensar nessa integração entre pesquisa e prática mesmo na pós-graduação, mas lembrando que nossa missão é primeiramente reflexiva e crítica. ${ }^{19}$

A porta giratória

Por outro lado, o próprio mercado de trabalho valoriza um título de mestre ou doutor, porque tais títulos significam no mínimo mais anos de escolaridade e, quiçá, mais contatos, os característicos "capital cultural" e "capital social" de que falava Pierre Bourdieu. E quando tais títulos são oferecidos pela universidade pública, na qual a excelência do corpo docente é garantida pela competitividade dos concursos de ingresso, melhor ainda. Mais capital simbólico, cultural e social eles carregam a um custo baixíssimo, financeiramente falando a um custo zero.

Isso acontece também pela estrutura da própria carreira jurídica. O curso de bacharelado habilita ao exercício de todas as profissões jurídicas. O bacharel presta um exame profissional ao sair da escola e, se tiver interesse, presta concurso público para ingressar em carreiras de Estado. Munido apenas do diploma de bacharel não pode, contudo, exercer a docência, e até recentemente a docência havia sido um mercado de trabalho alternativo. Os milhares de faculdades de Direito do Brasil, fáceis de criar e manter, baratas e rentáveis, foram até recentemente atraentes. Com os anos impuseramse, contudo, barreiras à entrada dos professores, de modo que de simples práticos, com gosto e tempo para ensinar nos cursos de Direito, foram sendo excluídos do campo, a menos que apresentassem um título de pós. Daí a corrida aos cursos de pós em primeiro lugar, e depois a corrida de todas as faculdades para poderem explorar esse novo e rentável filão do mercado.

Houve, portanto, uma pressão pela massificação, pressão a que a Faculdade de Direito respondeu pela ampliação crescente do número de docentes dispostos a orientar, sem, contudo, organizar-se academicamente. O programa ficou enorme, mas todos nós que dele participamos vimos a grande dificuldade para dar-lhe

19 Outras ciências veem-se às voltas com problemas semelhantes. Veja-se o caso da pesquisa em medicina molecular e pesquisas de intervenção clínica, que requerem uma combinação de muitas áreas (como a da epidemiologia, da antropologia, etc.). V. Barkin, S. S. (October de 2011). The challenge of facing translation of basic science into clinical and community settings to improve health outcomes. Environmental Health Perspectives, 119 (10), p. A418-A419. 
organicidade alguns anos atrás. Mesmo dispondo de títulos, experiência e excelência em suas respectivas áreas, os professores exclusivamente dedicados à pesquisa são ainda bastante poucos. Como resultado, a imensa maioria deles nunca apresentou a nenhuma agência de fomento um projeto de pesquisa. Não o apresentaram nem mesmo à própria universidade. O primeiro desafio do programa vem sendo, pois organizar-se de modo harmônico e poder oferecer linhas claras de investigação. Como elas procederiam de projetos dos professores líderes e estes nem sempre se apresentam com clareza, o programa sofre sob o peso de seu próprio gigantismo. ${ }^{20}$ Vivemos, portanto, diante de um paradoxo: um quadro excepcionalmente qualificado de professores, inclusive com redes internacionais de pesquisa e projetos inovadores, mas pouco articulado de um ponto de vista organizacional, sofrendo pressões externas tanto do mercado, em primeiro lugar, quanto da burocracia governamental.

Um curso de massa tende, portanto, a manter aberta, quando não a incentivar o uso da porta giratória entre mercado profissional e pesquisa. Disso resulta um prejuízo para a pesquisa propriamente dita. Aqui estamos diante de outro ponto a ser seriamente discutido nos cursos de pós-graduação em Direito pelo Brasil afora e a Faculdade de Direito da USP precisa estar preparada para essa discussão.

Conclusão

O programa de pós-graduação da Faculdade de Direito da USP, passado meio século de sua instituição no formato atual, encontra-se num momento privilegiado de escolhas de rumos. Ele é fruto direto de um momento importante de reforma da universidade brasileira, quando deixamos para trás - ou tentamos deixar para trás - muito do que havia sido herdado do modelo que poderíamos chamar "napoleônico" da universidade francesa, como a abolição das cátedras, a democratização dos órgãos de governo acadêmico, a valorização da pesquisa inovadora. Nem tudo saiu como esperado: abolidas as cátedras, os catedráticos mantiveram prestigio e influência, de certo modo continuaram com seu capital social e simbólico a dominar a vida departamental, especialmente numa faculdade como o Direito, em que pouca gente se formava no exterior e, portanto, não experimentava uma vida universitária diferente. Os limites da reforma seriam muitos, mas o fato importante é que ela trouxe inegável renovação. No caso da Faculdade de Direito da USP ela foi simultaneamente impactante no curso de graduação e de pós-graduação.

Pelo seu tamanho hoje incorpora certamente muita gente talentosa, mas incorpora também gente que não quer e não pode se tornar jurista acadêmico, pois claramente não é vocacionada à pesquisa, seja ela de base, seja ela aplicada. Sua "porta

20 Parece que há muitos outros programas com esse problema, sendo que o da USP não é nem mesmo o mais difícil de enfrentar. 
giratória" manteve-se relativamente aberta e algumas das pressões mencionadas acima não foram percebidas a tempo, ou não foram diagnosticadas de forma compreensiva. Precisa, pois, aprender a dividir espaço com cursos para bacharéis formados cuja intenção é adquirir uma especialização ou um nível de sofisticação profissional relevantes, mas não para serem professores ou pesquisadores. A experiência dos cursos de especialização ou de mestrado profissional podem ser muito importantes para benefício da própria pósgraduação acadêmica.

O mais relevante neste momento parece ser o esforço de pesquisa e de esclarecimento da natureza da pesquisa em Direito. Como em outras áreas de conhecimento talvez valha a pena usar uma distinção, polêmica, mas ainda útil, entre a pesquisa básica e a pesquisa aplicada em Direito. As duas são pesquisas e não se confundem com o simples estudo, especialização ou pura e simples busca de conhecimento. Nas duas ocorre novidade, não apenas novidade para o aluno, mas novidade para a comunidade toda. Os candidatos ao mestrado acadêmico e ao doutorado têm que ser preparados para criarem saber e não simplesmente aprenderem para si.

Diante do processo de massificação, a insistência no caráter inovador da pesquisa e da pós-graduação como espaço privilegiado em que ela se nutre é nosso maior desafio.

\section{Referências}

Ambrosini, D. R. (2010). Construcão de um sonho. (A. Angarita, Ed.) São Paulo: FGV - Escola de Direito.

Barkin, S. S. (2011 йил October). The challenge of facing translation of basic science into clinical and community settings to improve health outcomes. Environmental Health Perspectives, 119 (10), pp. A418-A419.

Barreto, O. (1968). Novos métodos em ensino do direito: a experiência norte-americana. Revista da Faculdade de Direito da Universidade de São Paulo, 63, 335-378.

Barreto, O. (1972). Plano de reforma do currículo do curso de graduação em direito. Revista da Faculade de Direito da Universidade de São Paulo, 67, 115-133.

Cardoso, F. H. (1968). Política e desenvolvimento em socieadades dependentes - Ideologias do empresariado argentino e brasileiro. São Paulo: Tese - Universidade de São Paulo.

Costa, P. J. (1972). A instalação dos cursos de pós-graduação a onze de agosto». Revista da Faculdade de Direito da USP, 67, pp. 343-350.

Cultura, M. d. (1983). Reforma Universitária: Relatório do Grupo de Trabalho criado pelo Decreto no. 62.937/68. MEC, Secretaria de Educação Superior, Brasília. 
Cunha, L. A. (2007). A universidade reformada: o golpe de 1964 e a modernização do ensino superior (2. ed.). São Paulo: Unesp.

Gordley, J. (1993). Mere brilliance: the recruitment of law professors in the United States. American Journal of Comparative Law, 41, 367-384.

Guimarães, A. S. (2002). Classes, raças e democracia. São Paulo, SP: Editora 34.

Hage, J. (2011). The method of a truly normative legal science. In: M. Van Hoeke, Methodologies of legal research: which kind of method for which kind of discipline? (p. 19-44). Oxford: Hart Publishing.

Kaldewey, D., \& Schauz, D. (2018). Basic and applied research: the language of science policty in the twentieth century. New York/Oxford: Berghahn Books.

Lacerda, G., Falcão, J., \& Rangel, T. (2012). Aventura e legado no ensino jurídico. Rio de Janeiro: FGV Direito Rio.

Loewenstein, K. (1944). Brazil under Vargas. New York, NY, USA: The MacMillan Company.

Motta, R. P. (2014). As universidades e o Regime Miliar. Rio de Janeiro, RJ: Zahar.

Rabban, D. (2013). Law's history: American legal thought and the transatlantic turn to history. Cambridge: Cambridge University Press.

Reale, M. (1987). Memórias - A balança e a espada. São Paulo: Saraiva. v. 2.

Van Hoecke, M. (2011). Legal doctrine: which method(s) for what kind of discipline. In: M. Van Hoecke, Methodologies of legal research: which kind of method for what kind of discipline? (p. 1-18). Oxford: Hart Publishing.

Venancio Filho, A. (1982). Das arcadas ao bacharelismo. 2. ed. São Paulo: Perspectiva.

\section{Documento oficial}

Ministério da Cultura (1983). Reforma Universitária: Relatório do Grupo de Trabalho criado pelo Decreto n. 62.937/68. MEC, Secretaria de Educação Superior, Brasília. 